\title{
All-Arthroscopic McLaughlin's Procedure in Patients with Reverse Hill-Sachs Lesion Caused by Locked Posterior Shoulder Dislocation
}

\author{
Emmanouil Brilakis ${ }^{1}$ Michael-Alexander Malahias ${ }^{1}$ Maria Patramani ${ }^{1}$ Grigoris Avramidis ${ }^{1}$ \\ Dimitrios Gerogiannis ${ }^{1}$ Angelos Trellopoulos ${ }^{1}$ Emmanouil Antonogiannakis ${ }^{1}$ \\ 13rd Orthopaedic Department, Hygeia General Hospital, Athens,
Greece \\ Address for correspondence Emmanouil Brilakis, MD, MSc, 30A \\ Street Aiolou, 17561 Palaio Faliro, Athens, Greece \\ (e-mail: Emmanuel.Brilakis@gmail.com).
}

Joints 2019;7:71-77.

\begin{abstract}
Keywords

- McLaughlin's procedure

- reverse Hill-Sachs lesion

- posterior shoulder dislocation

- arthroscopy

Purpose This study aims to investigate the clinical and functional outcomes of the allarthroscopic McLaughlin procedure in a clinical series of patients suffering by neglected locked posterior shoulder dislocation.

Methods A retrospective clinical study based on prospectively collected data was conducted in a single center regarding 10 patients with neglected locked posterior shoulder dislocation and concomitant reverse Hill-Sachs lesion, who were treated with the all-arthroscopic Mclaughlin procedure. The average humeral bone defect was $39 \pm 7 \%$ according to the preoperative computed tomography evaluation. The mean time of follow-up was $77 \pm 16$ months (range, 63-104 months).

Results No patient had suffered a new dislocation, whereas all of them were satisfied with the surgical outcome and returned to their previous activities of daily living. External rotation was restored to every patient studied from 0 degrees at the baseline. At the last follow-up, the median external rotation beside the body was 90 degrees (range, 50-90 degrees; $p<0.01$ ) and the respective measurement at 90 degrees of abduction was 90 degrees (range, $80-90$ degrees; $p<0.01$ ). The active forward flexion was increased $(p<0.01)$, from 60 degrees (range, $30-180$ degrees) at the baseline to 180 degrees (range, 160-180 degrees) at the last follow-up and the internal rotation was gained $(p<0.01)$ from the level of buttock (range, lateral thigh-T12) at the baseline to the T11 level (range, T7-L3) at the last follow-up. The median UCLA score was increased from 8 (range, 4-22) to 35 (range, 33-35; $p<0.01$ ) and the Oxford instability score from 5 (range, 3-16) to 46 (range, 43-48; $p<0.01$ ), respectively. Conclusion The arthroscopic McLaughlin procedure in substantial reverse Hills-Sachs lesion caused by locked posterior dislocation leads to excellent clinical and functional results in the long-term follow-up.

Level of Evidence This is a therapeutic study, case series with no comparison group, Level IV.
\end{abstract}

received

November 1, 2018 accepted after revision November 4, 2019 published online December 31, 2019
DOI https://doi.org/ $10.1055 / \mathrm{s}-0039-3401820$. ISSN 2282-4324. (c) 2019. The Author(s).

This is an open access article published by Thieme under the terms of the Creative Commons Attribution-NonDerivative-NonCommercial-License, permitting copying and reproduction so long as the original work is given appropriate credit. Contents may not be used for commercial purposes, or adapted, remixed, transformed or built upon. (https://creativecommons.org/ licenses/by-nc-nd/4.0/) Georg Thieme Verlag KG, Rüdigerstraße 14, 70469 Stuttgart, Germany 


\section{Introduction}

Posterior shoulder dislocations account for 2 to $5 \%^{1-3}$ of all shoulder dislocations. They usually occur as a result of a highenergy trauma associated with epileptic seizures or electrocution. ${ }^{4-6}$ This type of injury is often underestimated at the initial patient's evaluation, so that misdiagnosis might occur in 50 to $79 \%$ of all cases. ${ }^{7,8}$ This could be a result of inadequate physical examination, misinterpretation of plain radiographic films, or insufficient radiographic assessment. An average delay of 23.6 months has been reported concerning the time span between the injury and its precise diagnosis. ${ }^{9}$

Several treatment options have been described for the treatment of posterior shoulder dislocation. These options range from neglecting it to total shoulder arthroplasty depending on the functional status of the patient, the time elapsed between the injury and the diagnosis, the concomitant glenoid, and humeral head bone defects. ${ }^{10}$ There are still many controversies regarding surgical treatment, due to a lack of understanding, the pathomechanical issues leading to posterior instability. ${ }^{11}$ Traumatic posterior shoulder dislocations are often accompanied by a compression fracture on the anterior surface of the humeral head known as a "reverse Hill-Sachs lesion." This bony defect can engage on the posterior glenoid rim and subsequently lead to recurrent instability and progressive joint destruction. ${ }^{12}$ Open or arthroscopic surgical procedures can be accomplished to address humeral head defects and to restore joint stability. These operative techniques can be divided into nonanatomic and anatomic procedures. ${ }^{13}$ Regarding the open nonanatomic techniques, McLaughlin was the first to describe the reconstruction of the humeral bone defect, caused by posterior shoulder dislocation, with the transfer of subscapularis tendon insertion into the lesion. ${ }^{14}$ Different techniques to perform this procedure arthroscopically have been described in technical notes. ${ }^{12,15-17}$

Therefore, we conducted a clinical study to assess the clinical and functional outcome of the arthroscopic McLaughlin procedure for the treatment of patients suffering from locked posterior shoulder dislocation combined with reverse Hill-Sachs lesion. Our hypothesis was that this nonanatomic arthroscopic technique would be proven safe and efficient even in the treatment of large humeral bone defects.

\section{Methods}

This is a retrospective cohort study using prospectively collected data regarding the clinical and functional outcomes of patients with locked posterior shoulder dislocation who underwent an all-arthroscopic McLaughlin's procedure. These patients were treated in our department from January 2009 to December 2012. The main issues addressed in this study are the effect of this management (1) on the recurrence rate, (2) on the shoulder mobility, and (3) on the patients' function. The ability to return to the preinjury level of everyday and sporting activities is also examined. Approval was obtained from the Institutional Review Board (IRB) of our Hospital (ID number: 96/2013) according to the official guidelines of the Declaration of Helsinki. Informed consent was obtained from all the individual participants included in the study

\section{Participants}

Patients included in the study met the following eligibility criteria: (1) clinically and radiologically confirmed diagnosis of neglected unreduced traumatic posterior shoulder dislocation, (2) a bony defect $>20 \%$ of the humeral head based on the preoperative computed tomography (CT), (3) treatment with all-arthroscopic McLaughlin's procedure, and (4) at least 5 years of postoperative follow-up. We excluded all patients who had an acute and nonlocked posterior shoulder dislocation, patients with nontraumatic posterior shoulder dislocation, recurrent posterior shoulder dislocation, multidirectional shoulder instability, psychiatric patients, epileptic patients, patients suffering by systematic diseases, patients with substantial glenoid bone loss, and patients with previous shoulder surgery. In addition, we did not include in our study patients with a reverse Hill-Sachs lesion $<20 \%$ of the diameter of the affected humeral head, those with irreducible dislocation with closed method, those who were not treated with an allarthroscopic modified McLaughlin's procedure and all those who had postoperative follow-up less than 60 months.

All patients of this group had been involved in motor vehicle accident. These patients had been initially treated elsewhere with conservative means, as a result of a misdiagnosis. They suffered by mild-to-moderate pain which required oral analgesics. No patient had any neurological defect as result of their injury. The interval between the traumatic event and the operation was 2.7 months (range, 2 weeks-10 months).

\section{Intervention}

The operation was performed in lateral decubitus position, under interscalene brachial plexus block, in addition to general anesthesia with laryngeal mask and spontaneous breathing. Closed reduction was initially performed followed by standard shoulder arthroscopy. The cases that did not achieve closed reduction were excluded from this study. The degree of the glenoid bone loss was identified intraoperatively using a calibrated probe for measuring the anterior and the posterior radii of the inferior glenoid at the level of the bare spot. Bone loss was quantified as a percentage of the normal inferior glenoid diameter (assumed to be twice the anterior radius). Reverse Hill-Sachs lesions were also evaluated to confirm the preoperative $\mathrm{CT}$ assessment.

The tear of the posterior labrum was arthroscopically recognized, and a double-loaded absorbable anchor (Lupine, DePuy Synthes, Raynham, MA) was mostly used, inserted by the Port of Wilmington portal. The sutures of this anchor were passed through the capsule and labrum without being tied. The reverse Hill-Sachs lesion was then abraded with a burr, while one or two double-loaded anchors (depending on the size of the defect) were inserted in the lesion. The insertion was achieved through an anterior accessory portal made under direct supervision with the aid of a spinal needle. With the use of a suitable "suture passing" instrument (usually a Bird Beak, Arthrex, Naples, FL), the sutures were passed through the 
subscapularis tendon in a mattress fashion and tied over the lesion bringing the tendon in firm contact with the abraded surface of the humeral head. The knots were tied without passing the scope in the subacromial space. After confirming the adequate filling of the humeral head defect, the repair of the posterior complex was continued by tying the knots of the already inserted suture anchor and, finally, by implanting additional anchors as required (usually three double loaded anchors in total).

The operated shoulder was protected for 6 weeks in a brace of 30 degrees abduction and neutral rotation. The patient was allowed to remove the sling for exercising. Pendulum exercises, as well as elbow, and wrist range of motion (ROM) exercises were encouraged three times per day. Activities of daily living were allowed after the first few days as long as the motion of the shoulder was restricted to 90 degrees of forward flexion, 30 degrees of external rotation (ER), and no internal rotation. Active assisted exercises were started during the third postoperative week by gradual increase of the ROM. Until the eighth week, the program was focused on the recovery of glenohumeral ROM and the restoration of the scapular stability. Strengthening exercises of the shoulder were started at approximately 8 weeks postoperatively, whereas special attention was given to regain full ROM and dynamic stability of the joint. Overhead activities were allowed after 3 months and contact sports after 6 to 9 months postoperatively, depending on the progress of rehabilitation and the level of participation.

\section{Outcome Measurements}

A shoulder physical examination was performed preoperatively and in every follow-up visit. The range of motion of the shoulder was measured with a goniometer. Shoulder function was evaluated by the UCLA score and the Oxford instability score in every follow-up visit. The patients were postoperatively examined at 3 and 6 weeks, and then at 3, 6 , 9 , and 12 months, and every following year. Redislocation, subluxation, or a positive apprehension sign after surgery was defined as failure of the treatment. Any residual pain or other complaints were documented. Medical Research Council grading system was used for evaluating the muscle strength. ${ }^{18}$ This method involves testing the muscles against the examiner's resistance and grading the patient's strength on a 0 to 5 scale accordingly $(0=$ no muscle activation; $1=$ trace muscle activation, without achieving full range of motion; 2 =muscle activation with gravity eliminated, achieving full range of motion; $3=$ muscle activation against gravity; $4=$ muscle activation against some resistance; $5=$ muscle activation against examiner's full resistance).

Since all patients had already undergone a standard radiographic evaluation, usually with anteroposterior (AP) view, a CT scan (-Fig. 1) was performed to confirm diagnosis and measure the bony defect of the humeral head. The impression fracture was measured on the $\mathrm{CT}$ at the greatest diameter of the head and was expressed as the percentage of the projected total articular surface. ${ }^{19} \mathrm{~A}$ three-dimensional (3D) reconstruction was also used (- Fig. 2).

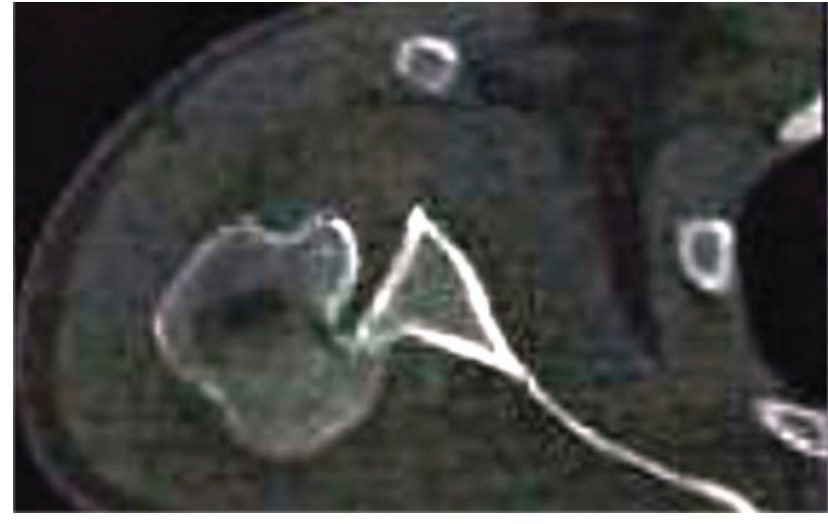

Fig. 1 Images from preoperative CT scan showing the posterior dislocation of the humeral head. The "locking" of the humeral head in the glenoid is depicted. $\mathrm{CT}$, computed tomography.

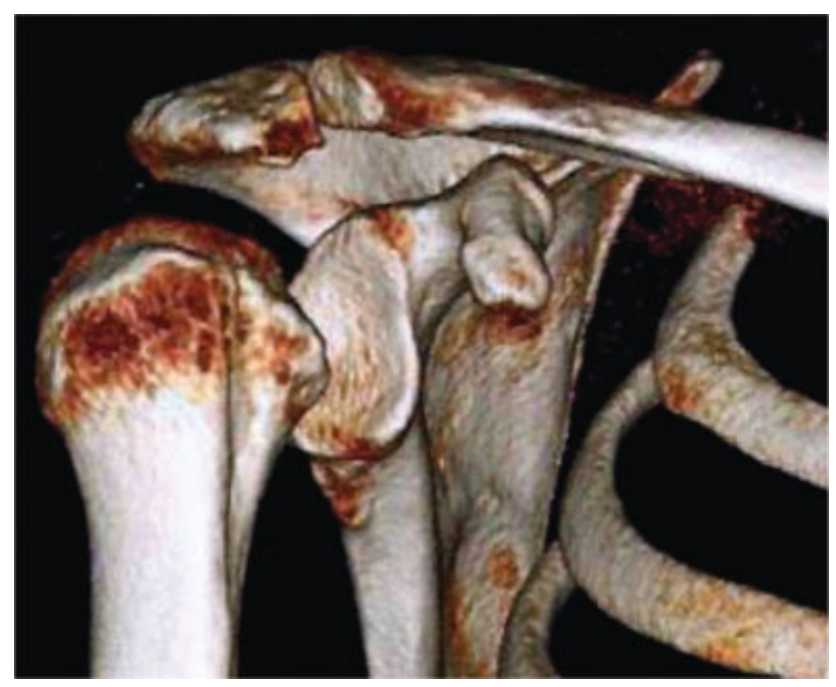

Fig. 2 Images from preoperative 3D CT scan showing the posterior dislocation from different views. 3D, three-dimensional; CT, computed tomography.

\section{Data Analysis}

Due to the small sample size, the distribution of the data analyzed did not meet the assumption of normality. Thus all the variables, either continuous (shoulder ROM apart from ER) or discrete (ER) or asymmetrical (functional tests), were reported as the arithmetic mean and 1 standard deviation, while discrete variables as the arithmetic median and ranging. The Wilcoxon's matched-pairs signed rank test was used to evaluate the differences between the preoperative and postoperative ROMs and functional scores. For all analyses, $p<0.05$ was considered to be statistically significant.

\section{Results}

A total of 10 patients met the inclusion criteria of this study. The demographic characteristics of these patients are depicted in - Table 1. All patients were males with a mean age of $49.8 \pm 12.1$ years (range, 29-73 years). Five shoulders (50\%) were right and five (50\%) were left. The dominant side was involved in eight patients (80\%). Eight patients $(80 \%)$ were involved in sporting activities; two were amateur 
Table 1 Demographic characteristics of the patients included in the study

\begin{tabular}{|c|c|}
\hline Number of patients included & $n=10$ \\
\hline $\begin{array}{l}\text { Age } \\
\text { (years) }\end{array}$ & $\begin{array}{l}49,8 \pm 12.1 \\
\text { (range, } 29-73 \text { ) }\end{array}$ \\
\hline $\begin{array}{l}\text { Gender } \\
\text { Male } \\
\text { Female }\end{array}$ & $\begin{array}{l}10(100 \%) \\
0(0 \%)\end{array}$ \\
\hline $\begin{array}{l}\text { Side } \\
\text { Left } \\
\text { Right }\end{array}$ & $\begin{array}{l}5(50 \%) \\
5(50 \%)\end{array}$ \\
\hline Dominant arm involved & $8(80 \%$ \\
\hline $\begin{array}{l}\text { Time interval between the injury } \\
\text { and the operation (months) }\end{array}$ & 2.7 (range, 0.5-10) \\
\hline $\begin{array}{l}\text { Sport participation } \\
\text { Amateur } \\
\text { Recreational }\end{array}$ & $\begin{array}{l}8(80 \%) \\
2(25 \%) \\
6(75 \%)\end{array}$ \\
\hline $\begin{array}{l}\text { Size of humeral bone defect } \\
\text { (\% of the projected } \\
\text { articular surface) }\end{array}$ & $39 \pm 7$ \\
\hline
\end{tabular}

athletes and six were recreational athletes. No professional athlete was involved in this study group. No patient lost to follow-up. The average follow-up was $77 \pm 16$ months (range, 63-104 months).

A shoulder physical examination was performed preoperatively by two experienced shoulder surgeons of our department. The total of the patients was found with an ER restriction ( $E R=0$ degrees). The active forward flexion (FF) was slightly reduced in four patients ( $F F>160$ degrees), significantly in two patients ( $160>\mathrm{FF}>120$ degrees), while four patients had major restriction with $\mathrm{FF}=60$ degrees. Active internal rotation (IR) was at the level of buttock, ranging from lateral thigh to $\mathrm{T}_{12}$.

The average humeral bone defect (reverse Hill-Sachs lesion) measured on preoperative $\mathrm{CT}$ scan was equal to $39 \pm 7 \%$. No concomitant fractures of the surgical neck or the lesser tuberosity were identified with the CT, while no signs of glenohumeral arthritis were found in our patients.

A small supraspinatus tear was found in a single patient (10\% of our sample) and was arthroscopically repaired. No patient included in this study had a glenoid bone loss $>7 \%$.

No patient suffered a new dislocation, whereas all patients (100\%) were satisfied with the surgical outcome and they returned to their previous activities of daily living. No patient developed stiffness.

The ROM of the shoulder is shown in - Table 2. Every patient participated in this study had full ER restriction ( $E R=0$ degrees) at the baseline. ER had been restored to each one of them at the last follow-up, since the median ER beside the body was 90 degrees (range, 50-90 degrees; $p<0.01)$ and the respective measurement at 90 degrees of abduction was 90 degrees (range, 80-90 degree $p<0.01$ ). The median active forward flexion was increased $(p<0.01)$ from 60 degrees (range, $30-180$ degrees) preoperatively to 180 degrees (range, 160-180 degrees) at the last follow-up.
Table 2 Comparison of shoulder range of motion and function between preoperative measurements and values at the latest follow-up

\begin{tabular}{|l|l|l|l|}
\hline Parameter & $\begin{array}{l}\text { Preoperative } \\
\text { median } \\
\text { (range) }\end{array}$ & $\begin{array}{l}\text { Latest } \\
\text { follow-up } \\
\text { median } \\
\text { (range) }\end{array}$ & $p$-Value \\
\hline Forward flexion & $\begin{array}{l}60 \text { degrees } \\
(30-180)\end{array}$ & $\begin{array}{l}180 \text { degrees } \\
(160-180)\end{array}$ & $<0.01$ \\
\hline $\begin{array}{l}\text { External rotation } \\
\text { beside the body }\end{array}$ & $\begin{array}{l}0 \text { degrees } \\
(0-0)\end{array}$ & $\begin{array}{l}90 \text { degrees } \\
(50-90)\end{array}$ & $<0.01$ \\
\hline $\begin{array}{l}\text { External rotation } \\
\text { at 90 degrees of } \\
\text { abduction }\end{array}$ & $\begin{array}{l}0 \text { degrees } \\
(0-0)\end{array}$ & $\begin{array}{l}90 \text { degrees } \\
(80-90)\end{array}$ & $<0.01$ \\
\hline $\begin{array}{l}\text { Internal rotation } \\
\text { Buttock } \\
(\text { lateral } \\
\left.\text { thigh- } \mathrm{T}_{12}\right)\end{array}$ & $\mathrm{T}_{11}\left(\mathrm{~T}_{7}-\mathrm{L}_{3}\right)$ & $<0.01$ \\
\hline UCLA score & $8(4-22)$ & $35(33-35)$ & $<0.01$ \\
\hline $\begin{array}{l}\text { Oxford instability } \\
\text { score }\end{array}$ & $5(3-16)$ & $46(43-48)$ & $<0.01$ \\
\hline
\end{tabular}

The median internal rotation was gained $(p<0.01)$ from the level of buttock (range, lateral thigh-T12) preoperatively to the T11 level (range, T7-L3) at the last follow-up (-Fig. 3).

Both the mean UCLA score and the Oxford instability score were significantly increased. The median UCLA score was increased from 8 (range, 4-22) preoperatively to 35 (range, 33-35) at the last follow-up $(p<0.01)$. Respectively, the mean Oxford instability score was increased from 5 (range, 3-16) preoperatively to 46 (range, 43-48) at the last follow-up $(p<0.01 ;-$ Fig. 4). The strength measured in forward flexion, abduction, ER, and internal rotation of the shoulder was normal (grade 5) for every patient at the last follow-up.

\section{Discussion}

The most important finding of the present study is the excellent clinical and functional outcome with the use of all-arthroscopic McLaughlin's procedure for patients suffering by locked posterior shoulder dislocation combined with substantial humeral head bone loss. Our case series presents the clinical outcomes regarding the arthroscopic repair of reverse Hill-Sachs lesion in patients with locked posterior shoulder dislocation. Despite the technical notes that had been published, ${ }^{15,18,20-22}$ this arthroscopic technique had yet not been clinically evaluated.

According to a systematic review, the management of posterior shoulder dislocation should be individualized for each patient based on the time of initial diagnosis, the size of the reverse Hill-Sachs lesion, and the associated injuries. ${ }^{10}$ The size of the impression fracture of the humeral head usually defines the treatment modality. ${ }^{20}$ The management of anteromedial defects remains challenging, especially considering defects between 25 and $40 \%$ of the articular surface which require a detailed preoperative planning. The development of advanced imaging modalities, such as the CT scanning with 3D 


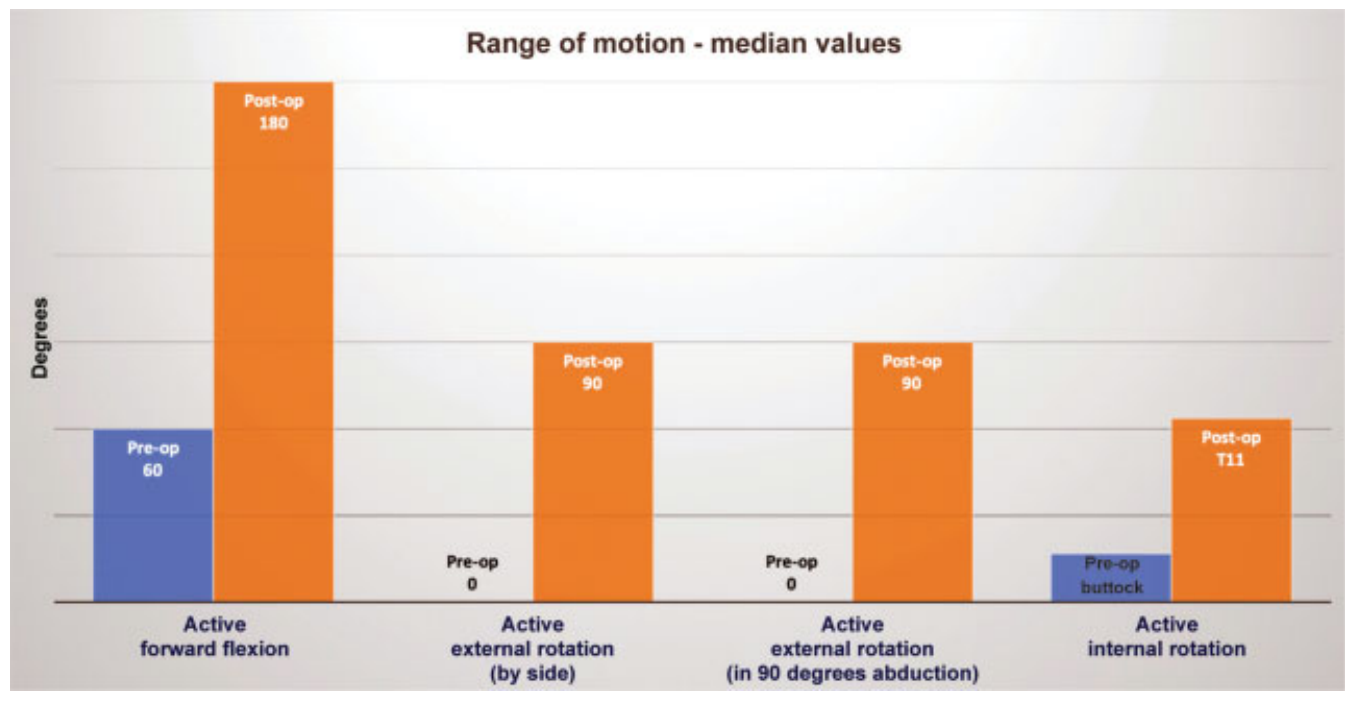

Fig. 3 Comparison of preoperative and postoperative range of motion. Pre-op, preoperative; Post-op, postoperative.

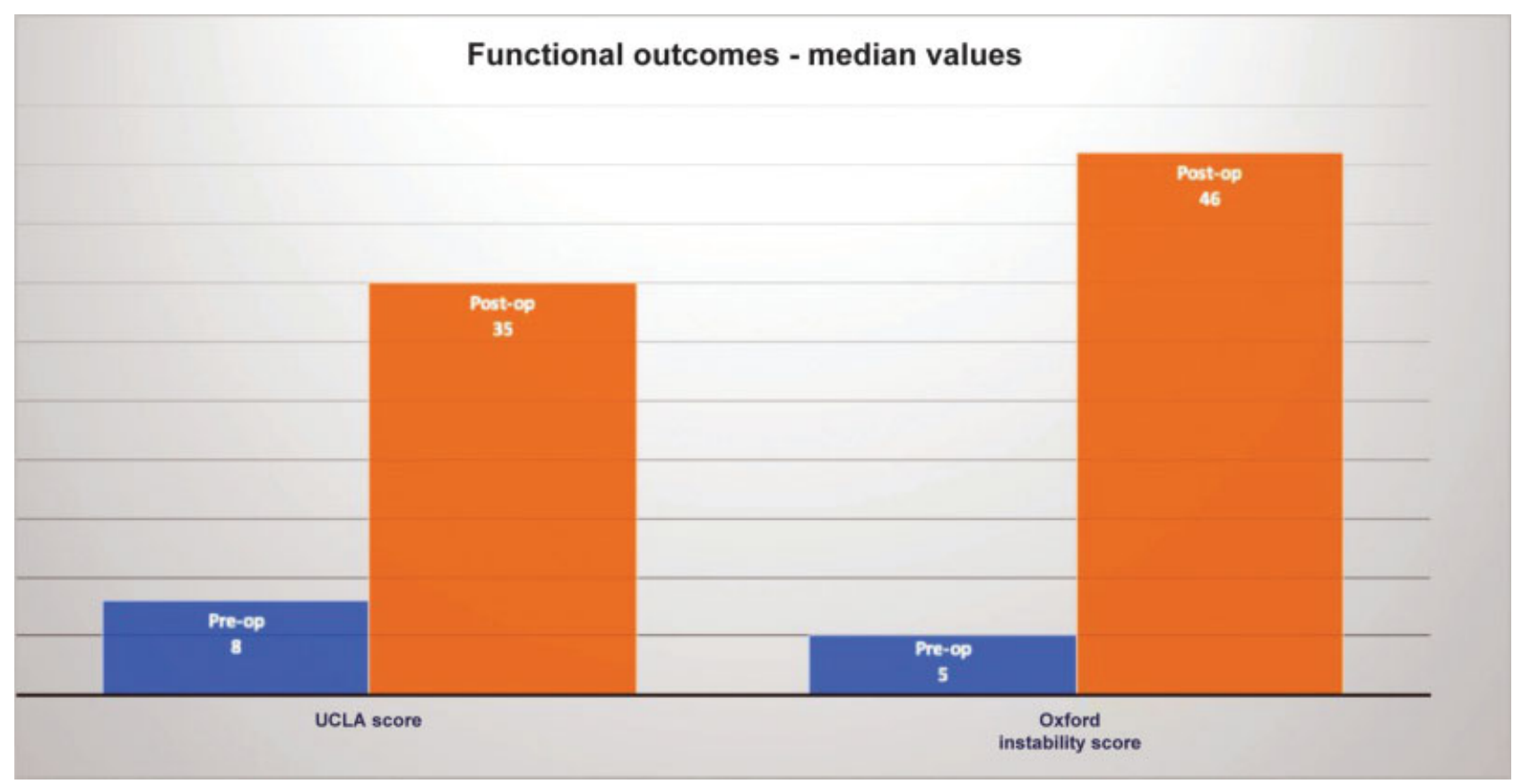

Fig. 4 Comparison of preoperative and postoperative functional outcomes. Pre-op, preoperative; Post-op, postoperative.

reconstruction, allowed better assessment of the humeral head bone loss. ${ }^{19}$

A variety of operations have been proposed as possible solutions for the treatment of these complex injuries. Various surgical approaches have been reported including arthroscopic repair, open nonanatomical muscle/tendon transfers, ${ }^{9,12,21,22}$ rotational osteotomies of the proximal humerus, ${ }^{23}$ anatomical bone grafting, ${ }^{24-27}$ and shoulder arthroplasty. ${ }^{28}$ The proposed arthroscopic techniques to address posterior shoulder dislocation include the repair of the posterior Bankart's lesion in combination with a capsular shift. ${ }^{12}$ However, in cases of substantial reverse Hill-Sachs lesions, the surgeon should also address the humeral head bony defects. At the middle of the previous century, McLaughlin ${ }^{14}$ was the first surgeon to recognize the significance of the impression fracture of the humeral head as for the treatment of chronic posterior dislocation of the shoulder. Neer ${ }^{29}$ modified the McLaughlin subscapularis transposition and transferred the lesser tuberosity with its attached subscapularis tendon en bloc to the defect.

There are only very few studies in the recent literature describing the nonanatomic operative treatment of chronic locked posterior dislocation of the shoulder. Shams et al evaluated the clinical outcome of open modified McLaughlin's procedure in 11 patients with locked chronic posterior shoulder dislocation and reverse Hill-Sachs defects. ${ }^{30}$ They concluded that reconstructing the reverse Hill-Sachs defect provides adequate stability, pain relief, and function in patients with locked chronic posterior shoulder dislocation, and a defect involving 25 to $50 \%$ of the humeral head. In another study, Demirel et al investigated the middle-term functional and 
radiological outcomes of the transfer of the lesser tuberosity in the management of reverse Hill-Sachs lesions following posterior dislocations of the shoulder. ${ }^{31}$ They reported satisfactory results at the last follow-up of 13 patients treated in an open manner. In a case report of a young male athlete with neglected locked posterior shoulder dislocation combined with reverse Hill-Sachs lesion, Steckel et al illustrated excellent clinical, functional, and radiological outcome after open modified McLaughlin's procedure ${ }^{32}$ Finally, in another case report, Charalambous et al described a modification of the open repair through deltopectoral approach and plication of the subscapularis tendon into the reverse Hill-Sachs lesion via two-bone anchors. ${ }^{21}$ The McLaughlin procedure was described to be performed arthroscopically ${ }^{16}$ with the use of suture anchors for fixing subscapularis tendon into the humeral bony defect. However, we found only level-V papers published (without any clinical outcome) regarding this arthroscopic modified McLaughlin's procedure. ${ }^{12,15-17}$ The present study is the first to investigate the clinical and functional results of the arthroscopic modified McLaughlin procedure. Particularly, all the clinical subjective scores (UCLA and Oxford instability score) used for the follow-up assessment of our patients were found statistically improved. Even more, the ROM of the shoulder was restored to normal to every patient participated in this study. Apart from that, it should be emphasized that there was no recurrence of instability in our series. This was possibly the result of the meticulous preoperative planning, the cautious reduction maneuvers, and the detailed arthroscopic evaluation. During the operation, special attention was given to suture the subscapularis tendon in the humeral head defect to close the gap, repair the posterior labral lesions, plicate the capsule (when it was considered necessary), and treat any other identified lesion. Special care was also taken in relation to the postoperative rehabilitation program, which should allow the soft tissue healing without any tension and discourage aggressive mobilization that might provoke recurrence of the instability.

\section{Limitations}

This study is not without limitations. Weak points were the retrospective design and the small number of patients. On the other hand, the data that we used were prospectively collected, whereas the rarity of this clinical entity justified the observational study design. Regarding the scarcity of patients with neglected locked posterior shoulder dislocation, the number of patients involved in our trial should be considered acceptable.

\section{Conclusion}

In conclusion, the arthroscopic McLaughlin procedure in substantial reverse Hills-Sachs lesion caused by locked posterior dislocation leads to excellent clinical and functional results in the long-term follow-up.

Conflict of Interest

None declared.

\section{References}

1 Cheng SL, Mackay MB, Richards RR. Treatment of locked posterior fracture-dislocations of the shoulder by total shoulder arthroplasty. J Shoulder Elbow Surg 1997;6(01):11-17

2 Gavriilidis I, Magosch P, Lichtenberg S, Habermeyer P, Kircher J. Chronic locked posterior shoulder dislocation with severe head involvement. Int Orthop 2010;34(01):79-84

3 Sperling JW, Cofield RH, Schleck CD, Harmsen WS. Total shoulder arthroplasty versus hemiarthroplasty for rheumatoid arthritis of the shoulder: results of 303 consecutive cases. J Shoulder Elbow Surg 2007;16(06):683-690

4 Bühler M, Gerber C. Shoulder instability related to epileptic seizures. J Shoulder Elbow Surg 2002;11(04):339-344

5 Cicak N. Posterior dislocation of the shoulder. J Bone Joint Surg Br 2004;86(03):324-332

6 Robinson CM, Aderinto J. Posterior shoulder dislocations and fracture-dislocations. J Bone Joint Surg Am 2005;87(03):639-650

7 Hatzis N, Kaar TK, Wirth MA, Rockwood CA Jr. The often overlooked posterior dislocation of the shoulder. Tex Med 2001;97 (11):62-67

8 Jones TP, Beckenbaugh JP, Sperling JW, Amrami KK, Sundaram M. Your diagnosis? Posterior shoulder dislocation. Orthopedics 2003;26(07):682

9 Checchia SL, Santos PD, Miyazaki AN. Surgical treatment of acute and chronic posterior fracture-dislocation of the shoulder. J Shoulder Elbow Surg 1998;7(01):53-65

10 Alepuz ES, Pérez-Barquero JA, Jorge NJ, García FL, Baixauli VC. Treatment of The Posterior Unstable Shoulder. Open Orthop J 2017;11:826-847

11 Lafosse L, Franceschi G, Kordasiewicz B, Andrews WJ, Schwartz D. Arthroscopic posterior bone block: surgical technique. Musculoskelet Surg 2012;96(03):205-212

12 Martetschläger F, Padalecki JR, Millett PJ. Modified arthroscopic McLaughlin procedure for treatment of posterior instability of the shoulder with an associated reverse Hill-Sachs lesion. Knee Surg Sports Traumatol Arthrosc 2013;21(07):1642-1646

13 Van Tongel A, Karelse A, Berghs B, Verdonk R, De Wilde L. Posterior shoulder instability: current concepts review. Knee Surg Sports Traumatol Arthrosc 2011;19(09):1547-1553

14 McLAUGHLIN HL. Posterior dislocation of the shoulder. J Bone Joint Surg Am 1952;24 A(03):584-590

15 Kelly BJ, Field LD. Arthroscopic transfer of the subscapularis tendon for treatment of a reverse Hill-Sachs lesion. Arthrosc Tech 2017;6(05):e2061-e2064

16 Krackhardt T, Schewe B, Albrecht D, Weise K. Arthroscopic fixation of the subscapularis tendon in the reverse Hill-Sachs lesion for traumatic unidirectional posterior dislocation of the shoulder. Arthroscopy 2006;22(02):227.e1-227.e6

17 Lavender CD, Hanzlik SR, Pearson SE, Caldwell PE III. Arthroscopic reverse remplissage for posterior instability. Arthrosc Tech 2016; 5(01): $443-\mathrm{e} 47$

18 James MA. Use of the Medical Research Council muscle strength grading system in the upper extremity. J Hand Surg Am 2007;32 (02):154-156

19 Moroder P, Tauber M, Hoffelner T, et al. Reliability of a new standardized measurement technique for reverse Hill-Sachs lesions in posterior shoulder dislocations. Arthroscopy 2013;29 (03):478-484

20 Diklic ID, Ganic ZD, Blagojevic ZD, Nho SJ, Romeo AA. Treatment of locked chronic posterior dislocation of the shoulder by reconstruction of the defect in the humeral head with an allograft. J Bone Joint Surg Br 2010;92(01):71-76

21 Charalambous CP, Gullett TK, Ravenscroft MJ. A modification of the McLaughlin procedure for persistent posterior shoulder instability: technical note. Arch Orthop Trauma Surg 2009;129(06):753-755

22 Finkelstein JA, Waddell JP, O'Driscoll SW, Vincent G. Acute posterior fracture dislocations of the shoulder treated with the Neer 
modification of the McLaughlin procedure. J Orthop Trauma 1995;9(03):190-193

23 Keppler P, Holz U, Thielemann FW, Meinig R. Locked posterior dislocation of the shoulder: treatment using rotational osteotomy of the humerus. J Orthop Trauma 1994;8(04):286-292

24 Gerber C, Lambert SM. Allograft reconstruction of segmental defects of the humeral head for the treatment of chronic locked posterior dislocation of the shoulder.J Bone Joint Surg Am 1996;78(03):376-382

25 Kokkalis ZT, Mavrogenis AF, Ballas EG, Papanastasiou J, Papagelopoulos PJ. Modified McLaughlin technique for neglected locked posterior dislocation of the shoulder. Orthopedics 2013;36(07): e912-e916

26 Mankin HJ, Doppelt S, Tomford W. Clinical experience with allograft implantation. The first ten years. Clin Orthop Relat Res 1983;(174):69-86

27 McDermott AG, Langer F, Pritzker KP, Gross AE. Fresh smallfragment osteochondral allografts. Long-term follow-up study on first 100 cases. Clin Orthop Relat Res 1985;(197):96-102
28 Wooten C, Klika B, Schleck CD, Harmsen WS, Sperling JW, Cofield $\mathrm{RH}$. Anatomic shoulder arthroplasty as treatment for locked posterior dislocation of the shoulder. J Bone Joint Surg Am 2014;96(03):e19

29 Neer CS. Fractures. In: Neer CS, ed. Shoulder Reconstruction. Philadelphia, PA: Saunders; 1990:394-395

30 Shams A, El-Sayed M, Gamal O, ElSawy M, Azzam W. Modified technique for reconstructing reverse Hill-Sachs lesion in locked chronic posterior shoulder dislocation. Eur J Orthop Surg Traumatol 2016;26(08):843-849

31 Demirel M, Erşen A, Karademir G, Atalar AC, Demirhan M. Transfer of the lesser tuberosity for reverse Hill-Sachs lesions after neglected posterior dislocations of the shoulder: A retrospective clinical study of 13 cases. Acta Orthop Traumatol Turc 2017;51 (05):362-366

32 Steckel H, Baums MH, Klinger HM. [Treatment of locked chronic posterior dislocation of the shoulder]. Sportverletz Sportschaden 2011;25(02):114-117 